\title{
GESTÃO DE PROTOCOLO: UMA PROPOSTA TEÓRICA DE NOVOS MODELOS \\ ORGANIZACIONAIS PARA A ADMINISTRAÇÃO PÚBLICA
}

\author{
PROTOCOL MANAGEMENT: A THEORETICAL \\ PROPOSAL OF NEW ORGANIZATIONAL MODELS FOR \\ PUBLIC ADMINISTRATION
}

Renata Lira Furtadoa

Felipe César Almeida dos Santos ${ }^{b}$

\begin{abstract}
RESUMO
Introdução: No contexto da Gestão de Documentos faz-se necessário compreender a relevância do serviço de Protocolo e as possibilidades de otimizar seus processos com a adaptação e implementação de modelos organizacionais nesses serviços. Objetivo: Demonstrar novos modelos organizacionais para a realização das atividades de Protocolo. Utilizando-se dos debates teóricos sob o Protocolo, centralização, descentralização e desconcentração na perspectiva da Arquivologia, a fim de elencar os elementos que respaldam a importância da utilização dos modelos organizacionais no Protocolo e entender como a escolha de um modelo afetará o programa de gestão de documentos de uma organização e elencar possíveis entraves que poderão ocorrer com a implementação de cada modelo. Metodologia: Pesquisa Bibliográfica em documentos impressos e eletrônicos, com autores da Arquivologia e Administração acerca das temáticas Gestão de documentos, Protocolo e Modelos organizacionais. Resultados: A pesquisa apresenta vantagens e desvantagens dos modelos organizacionais em uma possível aplicação em um serviço de Protocolo. Conclusões: A partir das discussões abordadas foi possível observar a intrínseca relação de codependência entre a Gestão Documental e o serviço de Protocolo, ressaltando a necessidade de uma atenção singular para com a aplicação de um modelo organizacional que possibilite maximizar a funcionalidade e a eficácia na prestação dos serviços.
\end{abstract}

Descritores: Protocolo. Arquivos. Gestão de Documentos. Modelos Organizacionais.

\footnotetext{
a Doutora em Ciência da Informação pela Universidade Estadual Paulista Júlio de Mesquita Filho (UNESP). Docente no Programa de Pós Graduação em Ciência da informação da Universidade Federal do Pará. E-mail: re23br@gmail.com

b Mestrando no Programa de Pós-Graduação em Ciência da Informação da Universidade Federal do Pará (PPGCI-UFPA). E-mail: felipecalmeidasa@gmail.com
} 


\section{INTRODUÇÃO}

Atualmente a produção de documentos tem se expandido de forma frenética e conduzir esse crescimento de forma sistemática tornou-se de suma importância, almejando conter o acúmulo de massa documental desordenada, visando o objetivo principal dos arquivos que é o acesso à informação.

À vista disso, é possível apreender que para o alcance dos propósitos citados é indispensável a administração da produção documental que se fará por intermédio de um programa de Gestão Documental eficiente e eficaz que visa à racionalização e uniformização das atividades de produção documental, garantindo o correto tratamento desde a criação do documento até seu destino final.

Entretanto, esse processo ainda é visto como um processo de pouca relevância ou algo que pode ser feito de qualquer forma, sem metodologia adequada, o que faz com que essa gestão em maior parte não ocorra de maneira funcional. Agregado à Gestão documental é essencial o serviço de Protocolo cujas atribuições estão vinculadas às atividades que vão do recebimento à expedição dos documentos.

É possível compreender que o serviço de Protocolo faz a vinculação dos usuários para com as unidades de uma instituição. Ferreira (1990 apud FREIXO, 2007) afirma que a unidade de Protocolo necessita ser inserida no programa de Gestão Documental, já que as atividades de Protocolo são consideradas parte da fase corrente. Assim sendo, o setor de Protocolo torna-se crucial para a instituição, dado que ele recebe, autua e tramita os documentos de acordo com suas particularidades.

No que tange a discussão acadêmica quanto ao serviço de Protocolo e os seus assuntos periféricos é irrefutável a necessidade de expansão deste debate, visto a limitada produção científica e as vastas possibilidades de exploração existente nos temas abordados.

Assim, este estudo visa discutir uma possível adaptação dos modelos organizacionais apresentados na literatura da Administração para o contexto de atuação dos serviços de Protocolo no âmbito da gestão documental, com o intuito de estabelecer novos modelos organizacionais para a realização dessas atividades. 


\section{GESTÃO DOCUMENTAL}

Desde seu surgimento nos Estados Unidos no final do século XIX, como um meio de otimizar o funcionamento e, sobretudo obter economia diante do crescente volume documental da administração pública, a Gestão de documentos em um primeiro momento, estava ligada à administração científica. Porém, nas últimas décadas essa prática vem sendo motivo de debates em diversas áreas do conhecimento, consolidando-se especialmente na Arquivologia.

De acordo com o Dicionário Brasileiro de Terminologia Arquivística Gestão de documentos é conceituada como:

Conjunto de procedimentos e operações técnicas referentes à produção, tramitação, uso, avaliação e arquivamento de documentos em fase corrente e intermediária, visando sua eliminação ou recolhimento. Também chamado administração de documentos. (ARQUIVO NACIONAL, 2005, p.100).

O termo "Gestão de documentos" não tem uma definição única, pois "uma vez que de sua elaboração e desenvolvimento participaram fatores determinantes, em que destaca uma dada e específica tradição arquivística, e também administrativa e um contexto histórico e institucional" (INDOLFO, 2007, p. 33-34). A gestão documental visa entender e organizar todo o processo do registro da informação até a destinação final, proporcionando controle, organização e disponibilização.

Dependendo do porte da instituição ao qual o arquivista irá atuar, disseminar que os produtores são responsáveis pelas primícias das funções arquivísticas leva tempo e mão de obra, mas como o documento necessita realizar seu trâmite do produtor ao receptor, existem mecanismos de entrada e trâmite interno de documentos nas instituições. Nesse contexto, o Protocolo é um órgão ímpar e parte integrante de um sistema de arquivos e oferece benefícios para gestão documental, que atua sobre os documentos na fase corrente, tornando-o responsável em prepará-los para as funções arquivísticas subsequentes. $\mathrm{Na}$ fase corrente o documento está recente e próximo ao provedor, isso facilita o entendimento, a identificação e a classificação desse registro informacional.

Desse modo, Machado e Camargo (2000) afirma por onde deve ser 
realizada a entrada de documentos e as operações ao qual eles serão submetidos:

\begin{abstract}
A entrada do documento na instituição deve ser realizada pela unidade orgânica do protocolo, é preciso dar realce a esse patamar inicial, onde estão compreendidas as operações de recebimento, classificação, registro, distribuição, tramitação e expedição (MACHADO; CAMARGO, 1999, p. 23).
\end{abstract}

Entende-se que a Gestão Documental possui sua gênese na produção do documento. Entretanto, para dar continuidade em uma Gestão Documental de qualidade é necessário, que o setor que possibilite a comunicação do usuário com a instituição e exerça suas atividades com máxima excelência.

\title{
3 PROTOCOLO
}

Etimologicamente o termo Protocolo é derivado do grego protokollon que faz referência a primeira folha que se anexava nos rolos de papiro ou livros, contendo um resumo do conteúdo dos documentos, dando-lhe uma informação inicial (SCHÄFER, 2015).

Com decorrer dos tempos, houve a necessidade da pluralização do conceito de Protocolo, podendo ainda conter traços do seu sentido etimológico, contemplando também um serviço ou um local de prestação desse serviço, conceito utilizado nesta pesquisa. O Dicionário Brasileiro de Terminologia Arquivística define Protocolo como:

Serviço encarregado do recebimento, registro, classificação, distribuição, controle da tramitação e expedição de documentos. Ver também arquivo corrente (2) e Unidade Protocolizadora. (p. 140)

Arquivo Corrente -1 . Conjunto de documentos, em tramitação ou não, que, pelo seu valor primário, é objeto de consulta frequentes pela entidade que o produziu, a quem compete a sua administração. 2. Arquivo responsável pelo arquivo corrente. ( $p$. 29)

Unidade Protocolizadora - protocolo responsável pela autuação de documentos. (p. 168) (ARQUIVO NACIONAL, 2005, grifo nosso)

Atualmente, o termo pode ser encontrado em outros Dicionários de Terminologia Arquivística de diferentes países. Apresenta-se no Quadro 1 as definições apresentadas por cinco países para a palavra Protocolo. 


\section{Quadro 1 - Conceitos de Protocolo}

\begin{tabular}{|c|c|c|}
\hline PAÍS & CONCEITO & TRADUÇÃO \\
\hline Costa Rica & $\begin{array}{l}\text { Libro o registro formal uma el cual el } \\
32 \text { la32oco da fe de las escrituras } \\
\text { emitidas, mediante uma transacción legal } \\
\text { (GARCÍA DE BENEDICTIS, 1994, p. 23) }\end{array}$ & $\begin{array}{l}\text { Livro ou registro formal em que o } \\
\text { notário atesta as escrituras } \\
\text { emitidas, através de uma transação } \\
\text { legal. }\end{array}$ \\
\hline Argentina & $\begin{array}{l}\text { 1. Folha que era usada como documento } \\
\text { para dar-lhe autenticidade, a princípio, } \\
\text { era a forma de verificação; } 2 \text {. Conjunto de } \\
\text { origens de escritas e outros documentos } \\
\text { protocolo que são mantidos no escritório } \\
\text { de cada notário. 3. Registro ou conjunto } \\
\text { de registros relativos a acordo } \\
\text { diplomático. (ARÉVALO JORDAN, 2003, } \\
\text { p.194). }\end{array}$ & \\
\hline $\begin{array}{l}\text { Estados } \\
\text { Unidos }\end{array}$ & $\begin{array}{l}\text { 1. The rules of etiquette and ceremony } \\
\text { that govern diplomatic relations between } \\
\text { states. - 2. A diplomatic document, } \\
\text { especially a treaty or compact, signed by } \\
\text { the negotiators but subject to ratification. } \\
\text { (PEARCE-MOSES, 2005, p. } 317 \text { ) }\end{array}$ & $\begin{array}{l}\text { 1. As regras de etiqueta e cerimônia } \\
\text { que regem as relações diplomáticas } \\
\text { entre os estados. } 2 \text {. Um documento } \\
\text { diplomático, especialmente um } \\
\text { tratado ou pacto, assinado pelos } \\
\text { negociadores mas sujeito a } \\
\text { ratificação. }\end{array}$ \\
\hline Canadá & $\begin{array}{l}\text { [documentary] The initial section of a } \\
\text { document, usually containing the } \\
\text { identification of the persons concurring to } \\
\text { its formation and of its temporal, } \\
\text { geographical and administrative context. } \\
\text { (DURANTI; PRESTON, 2008, p. 804) }\end{array}$ & $\begin{array}{l}\text { A seção inicial de um documento, } \\
\text { geralmente contendo a identificação } \\
\text { das pessoas que concorrem à sua } \\
\text { formação e de seu contexto } \\
\text { temporal, } \\
\text { administrativo. }\end{array}$ \\
\hline Itália & $\begin{array}{l}\text { gestione dei documenti: l'insieme 32la32 } \\
\text { attività finalizzate 32la registrazione di } \\
\text { 32la32ocolo e 32la classificazione, } \\
\text { organizzazione, assegnazione e } \\
\text { reperimento di documenti amministrativi } \\
\text { formati o acquisiti dall'Amministrazione, } \\
\text { nell'ambito del sistema di classificazione } \\
\text { adottato. (MULTILINGUAL ARCHIVAL } \\
\text { TERMINOLOGY, on line) }\end{array}$ & $\begin{array}{l}\text { Gestão de documentos: o conjunto } \\
\text { de atividades destinadas a registrar } \\
\text { o protocolo e a classificação, } \\
\text { organização, atribuição e } \\
\text { recuperação de documentos } \\
\text { administrativos formados ou } \\
\text { adquiridos pela Administração, } \\
\text { dentro do sistema de classificação } \\
\text { adotado }\end{array}$ \\
\hline
\end{tabular}

Fonte: Elaborado pelos autores (2019)

A partir da análise do conceito utilizado nos Dicionários e Manuais de Terminologia Arquivística supracitados, é possível inferir duas perspectivas quanto ao conceito do termo Protocolo. A primeira enxerga que o termo visa garantir o valor jurídico e que o documento possa ser tramitado de forma legal, ou seja, objetivando a autenticidade. Enquanto o outro caminha por um viés organizacional, tendo como propósito o controle documental.

Independente do âmbito ao qual ela pertence, uma instituição possui uma 
produção orgânica e não orgânica de documentos referentes às suas atividades, são registros compostos de informações fundamentais, que vão desde a criação, regulamentação e execução de serviços. O Protocolo como unidade, atua especialmente com o controle de documentos em fase corrente, essa fase conceitua-se pelo Dicionário de Terminologia Arquivística (1996), como sendo:

[...] o conjunto de documentos estritamente vinculados aos objetivos imediatos para quais foram produzidos no cumprimento de atividades fim e meio e que se conservam junto aos órgãos produtores em razão de sua vigência e frequência com que são por eles consultados. (CAMARGO; BELLOTTO, 1996 p. 6)

Dessa forma, o setor de Protocolo torna-se crucial em uma organização, considerando que sua função é intrinsecamente ligada a garantia de acesso às informações de forma ágil e precisa, proporcionada por procedimentos eficazes e eficientes, conferindo maior segurança à tomada de decisão (ALVES; SOUSA, 2017). De acordo com Brasil (2015), cabe ao Protocolo o desenvolvimento das atividades elencadas no Quadro 2:

\section{Quadro 2 - Funções de protocolo e suas atividades}

\begin{tabular}{|c|c|}
\hline FUNÇÃO & ATIVIDADE \\
\hline Recebimento & $\begin{array}{l}\text { Verificar se o documento destina-se ao órgão ou entidade, separando os } \\
\text { documentos de caráter oficial daqueles de caráter particular. }\end{array}$ \\
\hline Classificação & $\begin{array}{l}\text { Classificar os documentos quanto aos seus assuntos relativos às } \\
\text { atividades-meio de acordo com as classes aprovadas pelo Conselho } \\
\text { Nacional de Arquivos, e o relativos às atividades-fim de acordo com as } \\
\text { classes elaboradas por cada órgão ou entidade e aprovadas pelo Arquivo } \\
\text { Nacional. }\end{array}$ \\
\hline Registro & $\begin{array}{l}\text { Registrar informações dos documentos em Sistema Informatizado ou } \\
\text { excepcionalmente em formulário, no qual constarão dados } \\
\text { identificadores. }\end{array}$ \\
\hline Distribuição & Processo de endereçar os documentos aos seus destinatários. \\
\hline $\begin{array}{l}\text { Contr } \\
\text { Trami }\end{array}$ & $\begin{array}{l}\text { Procedimentos realizados visando o mapeamento do trâmite dos } \\
\text { documentos. }\end{array}$ \\
\hline Expedição & $\begin{array}{l}\text { Procedimento de encaminhar da documentação ao destinatário externo a } \\
\text { uma instituição. }\end{array}$ \\
\hline Autuação & $\begin{array}{l}\text { Ato obrigatório quando o assunto requerente requer análise, informações, } \\
\text { despachos pareceres ou decisões administrativas do órgão ou entidade. }\end{array}$ \\
\hline
\end{tabular}

Fonte: Elaborado pelos autores (2019)

Assim, é possível compreender o quão as atividades de Protocolo necessitam de uma atenção e de um cuidado duplicado e que lapsos em seus 
procedimentos ocasionariam acúmulos desordenados, por sequência, comprometendo a qualidade das atividades. Desencadeando problemas que confrontam o objetivo dos arquivos, o acesso à informação.

A gestão documental visa entender e organizar todo o processo do registro da informação até a destinação final, proporcionando controle, organização e disponibilização. A vinculação entre as atividades de Protocolo e a Gestão Documental são quase intrínsecas em instituições que trabalham sem erros.

Assim, é notório que as atividades de protocolo são determinantes para a concreta implementação de uma política de gestão de documentos em instituições e organizações públicas, pois todas suas atividades culminam com a garantia de recuperação e posterior acesso a informação.

Dessa forma, torna-se cada vez mais destacada a estreita relação da Gestão Documental e do setor de Protocolo. Ao ponto de ser factível reconhecer os procedimentos com as ações técnicas relativas a produção e tramitação de documentos em fase corrente, na composição do art. $3^{\circ}$ da Lei ํㅛ.159, de janeiro de 1991:

Art. $3^{\circ}$ - Considera-se gestão documental o conjunto de procedimentos e operações técnicas referentes a produção, tramitação, uso, avaliação e arquivamento em fase corrente e intermediária, visando a sua eliminação ou recolhimento para guarda permanente.

Dessa maneira, é possível depreender que as atividades da unidade não apenas compõem, mas são vitais à eficácia do programa de Gestão Documental, pois ao registrar e controlar o trâmite dos documentos, os protocolos completam uma função medular para garantir a agilidade do processo decisório, assim como proporcionar a avaliação e controle interno e externo da Administração Pública. E para estar em harmonia com as exigências de disponibilização de informações previstas na Lei no12.527/2011, as unidades protocolizadoras necessitam passar a exercer um papel ainda mais estratégico nas instituições, pois apenas com sua eficácia e um desempenho satisfatório de suas atribuições será possível a obtenção de conformidade com a Lei de Acesso a Informação.

Portanto, deixa-se mais do que claro a relevância da maximização, tanto da eficiência quanto da cautela na execução das atividades do Protocolo. Por conseguinte, torna-se fundamental analisar de forma minuciosa qual modelo 
organizacional será aplicado na unidade que contribuirá à garantia dessa maximização.

\section{MODELOS ORGANIZACIONAIS}

A administração pública brasileira foi marcada por métodos de reforma que em uma ótica histórica, foram entendidas por Klering, Porsse e Guadagnin (2010) como transformações da estrutura administrativa que objetiva à superação de obstáculos institucionais e gerenciais do setor público.

Nessa mesma perspectiva, a adoção de novos modelos organizacionais para a aplicação nos setores de Protocolo deve ser vista por parte do plano de Gestão Documental de uma instituição, com o intuito de superar as barreiras que dificultam a execução de atividades da unidade protocolizadora.

Tradicionalmente o modelo adotado para a atuação do Protocolo é o de centralização de suas atividades, que pode até atender suas demandas de forma satisfatória. Todavia, não há uma fórmula a ser seguida para obter o contentamento nas atribuições deste serviço. Cada instituição constitui-se como um universo singular com suas demandas e características particulares e que devem ser tratadas de forma análoga.

Torna-se evidente que as instituições e organizações são uma das mais afetadas pela carência, tanto de um programa de Gestão Documental eficiente, quanto de uma maximização da eficácia das atividades do Protocolo. Um dos causadores destes problemas é a naturalização da realização das atividades arquivísticas por indivíduos não capacitados e de autorização indeferida.

Dessa forma, a presente seção visa elencar alguns dos modelos organizacionais existentes e como estes podem impactar a execução das atividades de Protocolo, pontuando as vantagens e desvantagens que cada um poderá proporcionar caso sejam implementados. Dentre os vários modelos existentes, serão apresentados a Centralização, Descentralização e Desconcentração.

Para tanto, é valido salientar que no contexto arquivístico a unidade de Protocolo está hierarquicamente subordinada a Unidade de Arquivo, independente do modelo organizacional aplicado em uma instituição. Serão 
apresentados então possibilidades de utilização de modelos organizacionais com enfoque para sua adaptação em serviço de Protocolo.

\subsection{Centralização}

É a concentração de autoridade, ou seja, a acumulação e o uso da competência de deliberação sob a administração de um único setor, tendo suas subunidades sujeitas às orientações recebidas.

A centralização enfatiza as relações escalares, isto é, a cadeia
de comando. A organização é desenhada dentro da premissa de
que o indivíduo no topo possui a mais alta autoridade que a
autoridade dos demais indivíduos é escalada para baixo, de
acordo com sua posição relativa no organograma.
(CHIAVENATO, 2003, p. 162)

Dessa forma, estabelecendo um planejamento organizacional dividido em dois níveis hierárquicos, o primeiro sendo de natureza estratégica com a gerência das decisões que afetarão a organização, e o seguinte de características operacionais, que possuem contato direto com a realização das atividades.

A partir disso, a utilização deste modelo organizacional no campo da arquivística, aplicado ao setor de Protocolo, ocasionará na necessidade de elaboração de um planejamento estratégico e de resoluções de conflitos nas incumbências do Arquivo, sendo este a instância máxima de deliberação dos assuntos voltados a produção documental de uma organização. Ou seja, o Arquivo Central ocuparia o mais alto nível de autoridade, o nível estratégico. E o Protocolo ocuparia um nível de autoridade inferior, o nível operacional. Conforme mostra a Figura 1:

Figura 1 - Modelo de aplicação de gestão de Protocolo Centralizado

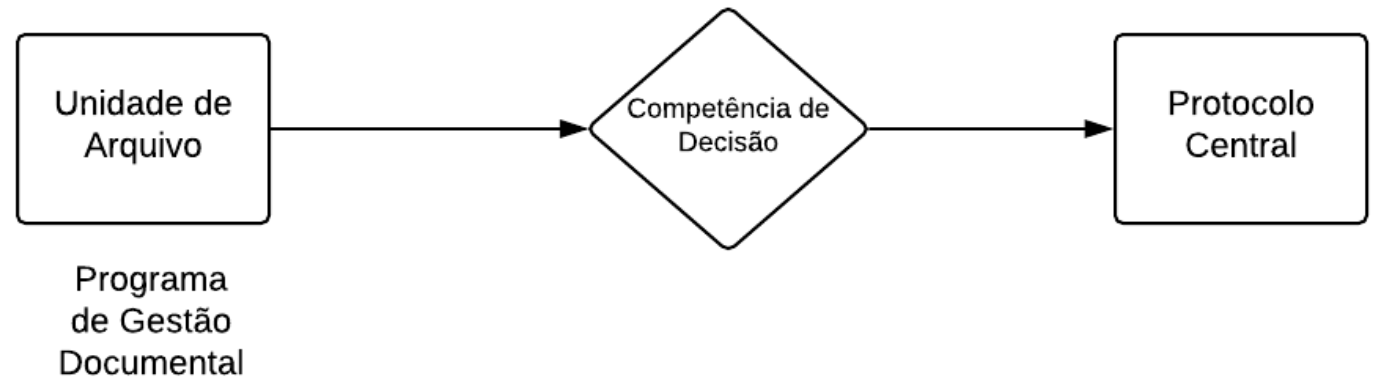

Fonte: Elaborado pelos autores (2019) 
Compreende-se a partir disso, que os gestores do Arquivo Central deverão pautar suas ações em consideração à totalidade da instituição, mesmo que um problema seja específico de um determinado Protocolo setorial a resolução deste entrave beneficiaria todas as unidades protocolizadoras da instituição, podendo ser exemplificado com a padronização de normas e procedimentos a serem aplicados com a documentação de uma instituição.

Ainda nesse contexto, Chiavenato (2003) pontua que os detentores do mais alto nível de autoridade de uma organização, neste caso o Arquivo Central, necessitam de preparo para gerir e exercer suas atribuições de forma a se manterem atualizados quanto as formas de atender as necessidades do Protocolo.

No entanto, manter a competência de decisão distante do seu campo operacional, quando mal gerenciado, poderá acarretar ruídos na comunicação, sendo capaz de provocar a demora na resposta em determinada situação. Geralmente, os gestores estratégicos do Arquivo Central não possuem o conhecimento do cotidiano da operacionalização das ações executadas no Protocolo. Estes compreendem como seria o funcionamento ideal do setor, contudo esta perspectiva parcial não os permite observar a enérgica rotina da unidade protocolizadora, tanto no que se refere a documentação quanto ao público atendido.

Ainda nesse cenário, a ótica limitada do setor de gestão não percebe a necessidade do Protocolo de acompanhar a dinâmica de suas atribuições. Dessa forma, o que escapa do entendimento do Arquivo Central pode não ser tradado com a importância devida, prejudicando o bom funcionamento da unidade.

\subsection{Descentralização}

A Descentralização não é um conceito moderno nas obras que discutem modelos organizacionais na administração pública, esta discussão vem inserida pincipalmente no movimento de democratização e participação (JUNQUEIRA, 1998). O autor ainda define, como um processo de translucidez de poder dos 
níveis centrais para os periféricos.

Entretanto, mesmo que não haja consenso quanto ao seu conceito, em um olhar liberal aborda o termo como uma tática para reestruturar o sistema administrativo, não objetivando minimizá-lo, mas para torná-lo mais eficaz e ágil.

A descentralização, como um método que define de maneira dialética em comparação à centralização, é a oportunidade de trazer o debate sobre as políticas de gestão de Protocolo e suas tomadas de decisão para junto do seu espaço de ação e seus indivíduos executores de funções. De acordo com Medauar (2004):

[...] Descentralização administrativa significa a transferência de poderes de decisão em matéria específica a entes dotados de personalidade jurídica própria. [...] assim, a transferência de atividade decisória e não meramente administrativa. (apud BAPTISTA, 2011, p. 20)

No entanto, o que compete a essa pesquisa é a viabilização do modelo organizacional descentralizado para aplicação nas Unidades de Protocolo de instituições e/ou organizações. Conforme demostra a Figura 2:

Figura 2 - Modelo de aplicação de gestão de Protocolo Descentralizado.

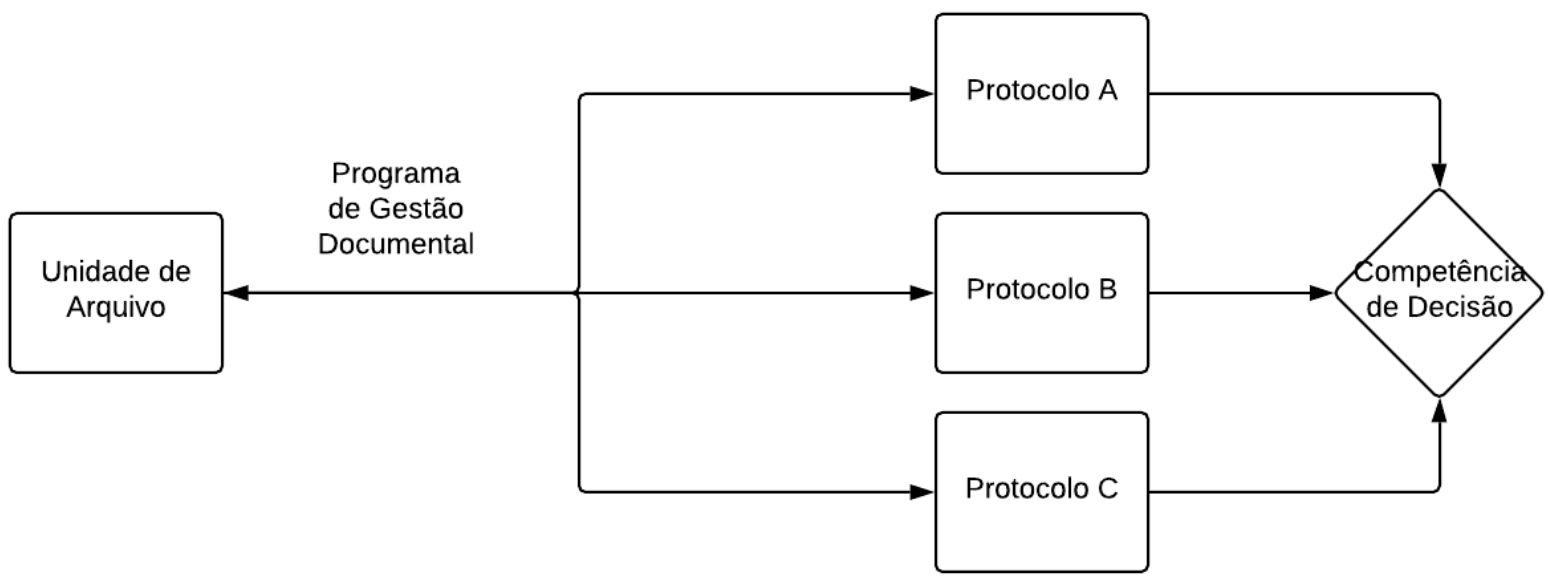

Fonte: Elaborado pelos autores (2019)

Desse modo, a descentralização dará a Unidade Protocolizadora abertura para propor ferramentas estruturantes ao sistema informatizado utilizado pela instituição, que facilitem o controle da tramitação e recuperação de informações, atendendo de forma satisfatória as especificidades que cada subunidade possa 
possuir, não dependendo mais das decisões realizadas pela Unidade de Arquivo.

Ademais, este processo contribuirá com as mudanças no controle das movimentações dos processos, pois ao contrário da gestão centralizada neste tipo de gestão os processos possuem sua autuação e arquivamento ligados ao mesmo setor, ou seja, os documentos de teor administrativo terão seu início no protocolo do setor administrativo e seu término no arquivo da mesma unidade.

Desse modo, podemos inferir que o modelo de descentralização possibilitará uma visão singular às necessidades especificas vivenciadas no setor, podendo acarretar em mais rapidez na resolução de conflitos e problemas, visto que cada Unidade terá um serviço de Protocolo próprio e este será especializado nas demandas e serviços inerentes do setor, por esse motivo tendo mais autonomia na tomada de decisão a fim de resolver os empasses apresentados.

Além disso, ao mesmo tempo que proporciona mais rapidez e eficácia, viabiliza a agilidade na expedição e distribuição da documentação recebida. Eventualmente, minimizará a possibilidade de acúmulos e lentidão na efetivação de suas atividades.

Todavia, faz-se necessário entender que o processo de descentralização do poder para uma unidade ainda à faz pertencente a uma engrenagem de sistema maior, a Instituição. Tendo que haver consonância das decisões para que estas caminhem concomitantemente em função do objetivo maior da instituição.

Desse modo, a fragmentação da competência de decisão poderá obter como produto o julgamento de pequenas situações afetando de forma nociva o conjunto maior, impossibilitando o bom andamento de uma organização. Pois resoluções de problemas de natureza local não significam a resolução de entraves de cunho coletivo.

\subsection{Desconcentração}

A desconcentração vem do ato da fragmentação sistêmica de competências não acompanhada da competência decisória, ou seja, são distribuídas a execução de atividades acumuladas, com o intuito de desanuviar 
o acúmulo de atribuições de um setor, submetido as deliberações de uma unidade hierarquicamente superior.

Chiavenato (2003) ao empregar as ideias de centralização de comando e de descentralização de exercício, mesmo sem utilizar a nomenclatura, abordou o modelo organizacional de desconcentração aqui estudada:

Centralização de comando: São as decisões concentradas na cúpula da organização. [...] Descentralização da execução: Significa que as tarefas são descentralizadas e delegadas para o pessoal que trabalha na base da organização, ou seja, no nível operacional. (CHIAVENATO, 2003, p. 44)

O autor utiliza os termos dentro do exemplo de uma organização militar, cujo o comando é centralizado em um indivíduo de patente maior, mas a execução é realizada por outros de patente inferior.

Conduzindo o conceito abordado ao campo arquivístico, o modelo organizacional em sua aplicação poderá produzir Protocolos Setoriais especializados para cada Unidade que demande esta atividade em uma Instituição, sendo estes hierarquicamente inferior ao Protocolo Central. Dessa forma, cada Setorial realizará suas atividades sob a autoridade do Protocolo Central, que será o imediato detentor de tomada de decisões quanto aos procedimentos de protocolo a serem executados na instituição, em concordância com as decisões da Unidade de Arquivo, assim como mostra a Figura 3.

Figura 3 - Modelo de aplicação de gestão de Protocolo Desconcentrada.

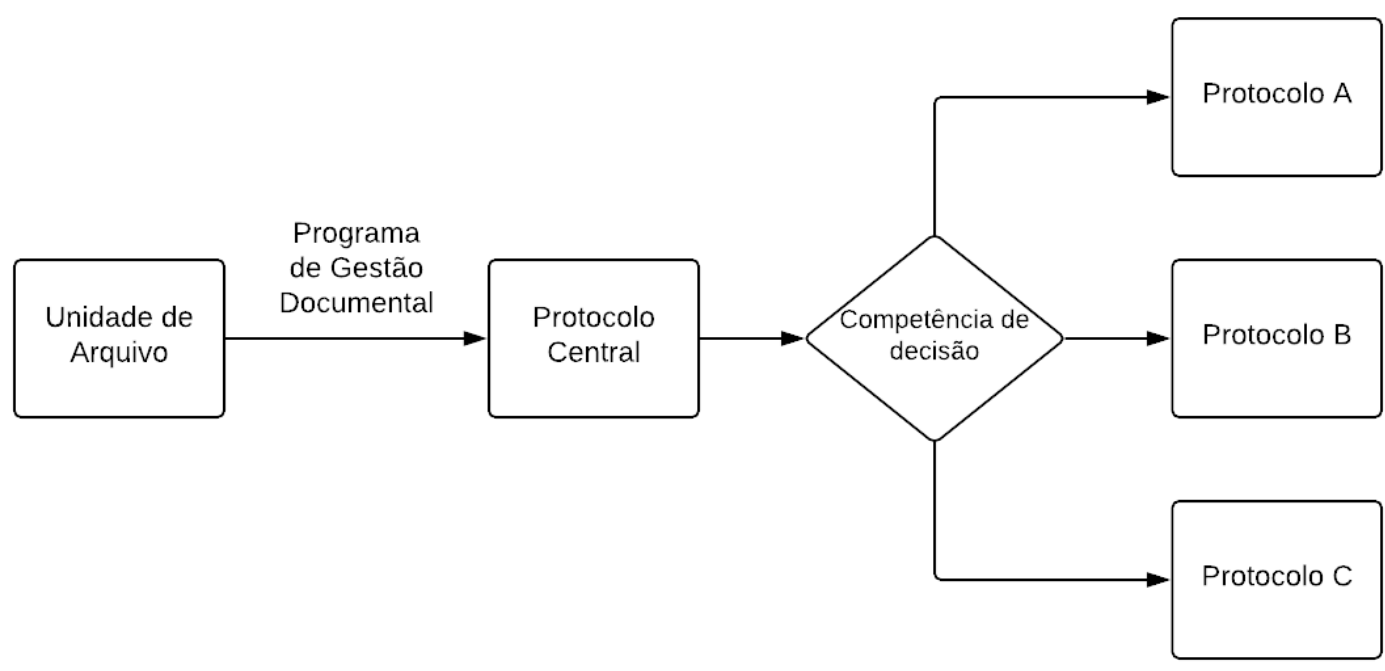

Fonte: Elaborado pelos autores (2019) 
Ademais, os processos de recebimento, distribuição, expedição, controle e guarda serão executados pelos Protocolos Setoriais de maneira similar ao que aconteceria no modelo de Gestão Descentralizado, diferenciando-os pelo fato de que os Protocolos Setoriais do modelo Desconcentrado não possuirão autonomia quanto a tomada de decisão referentes aos documentos autuados, uma vez que o Protocolo Central irá gerenciar as atribuições arquivísticas dos Protocolos Setoriais. Ou seja, fazendo-se valer de grande parte das vantagens de um Protocolo Descentralizado somado aos proveitos de se ter as decisões centralizadas em um Protocolo Geral.

Pode-se dizer que o processo de desconcentração acumula grandes benefícios, logo, a partir da sujeição dos Protocolos Setoriais às decisões oriundas do Protocolo Central, faz-se necessário o conhecimento minucioso por parte do Central tanto das atribuições em comum de protocolo, quanto das específicas de cada Setorial, a fim de que o processo decisório contemple de forma satisfatória as demandas, tanto micro, quanto macro, da instituição.

Portanto, quando não há compreensão desta necessidade por parte da Unidade deliberativa, poderá ser comum divergências na comunicação entre as unidades, sendo capaz de desencadear problemáticas que inviabilizarão a continuidade dos serviços fundamentais de protocolo.

A realização de desconcentração de atividades, quaisquer que elas sejam, necessitam de um planejamento para que ocorra de forma sistêmica. Dessa mesma forma precisa ocorrer na aplicação em um setor de Protocolo, para que a Unidade Central possua o preparo para oferecer o suporte necessário às suas subunidades, pois de nada valerá a aplicação deste modelo organizacional, que visa a fragmentação de atividades para melhoria da fluidez de atribuições, se a mesma gera mais obstáculos do que os soluciona.

Por fim, a execução de atividades desvinculadas da autonomia de tomada de decisão necessita de um meticuloso planejamento para sua aplicação. Pois o programa organizacional das instituições deve caminhar de forma uníssona em todas as suas esferas para que o propósito de uma adequação de modelos organizacionais contemple a necessidade de sua utilização. 


\section{CONSIDERAÇÕES FINAIS}

A partir das discussões abordadas na presente pesquisa, tornou-se claro a intrínseca relação de codependência entre o Protocolo e a Gestão Documental, tendo em vista que a Gestão Documental visa promover a produção e a utilização sistêmica de documentos para munir uma instituição de ferramentas que auxiliem no alcance do objetivo da produção do documental. Da mesma forma que a Unidade de Protocolo objetiva a garantia do controle da tramitação e recuperação das informações de maneira rápida e eficiente sempre que necessário.

Ao se tratar da Unidade Protocolizadora e suas atribuições, entende-se que ter o controle do recebimento ao trâmite dos documentos requer a otimização de suas ferramentas e de sua operacionalidade para o alcance do seu objetivo. E para isso demanda a utilização de uma Gestão Documental potencializada para seu funcionamento ideal.

Em contraponto, a Gestão documental em suas particularidades também necessita entender, com primazia, a relevância do setor de Protocolo para a realização de suas atividades, visto que para a obtenção do uso correto das informações contidas nos documentos faz-se necessário o registro adequado e o conhecimento do trâmite no qual o documento irá ter.

Para que isso ocorra de forma saudável, faz-se necessário pensar qual o melhor modelo organizacional a ser aplicado para obter a otimização do setor de Protocolo e do programa de Gestão Documental, de forma simultânea, para que possam resultar nos seus objetivos, de modo favorável.

Dessa maneira, faz-se necessário um olhar mais atento paras as funções do Protocolo. Primeiramente, o processo de recebimento da documentação para autuação, dentro de uma gestão descentralizada ocorreria de forma mais ágil devido a competência de tomada de decisão ser de atribuição dos Protocolos Setoriais, o que não seria possível dentro de modelos centralizados e desconcentrados. Entretanto, dentro de uma organização centralizada torna-se mais fácil propor modificações pensadas na realidade macro, visto a centralidade da competência de comando, do que se teria em modelos descentralizados e 
desconcentrados. Por fim, proporcionar a preocupação central de uma unidade exclusivamente na execução de suas atribuições, assim feita pelo modelo desconcentrado, não sendo algo palpável em modelos centralizados e descentralizados.

Portanto, não há como ser definir um modelo organizacional que elevará a eficácia da unidade protocolizadora e do programa de Gestão Documental. Mas sim, que se torna primordial entender a realidade da instituição a fim de se propor um modelo organizacional que melhor atenda às suas necessidades e demandas.

Dessa forma, para além desta pesquisa torna-se indispensável o prolongamento do estudo quanto a gestão de protocolo, levando em consideração a existência de inúmeros outros paradigmas organizacionais, não abordados neste trabalho, que podem ser aplicados a uma Unidade Protocolizadora.

Por fim, dentro deste tema encontra-se a necessidade de expandir o quantitativo de produções científicas, tendo em vista a dificuldade de obtenção de material de referência para a elaboração e fundamentação desta discussão, além de promover novas perspectivas sobre o agir e o fazer da unidade de Protocolo.

\section{REFERÊNCIAS}

ALVES, Ítalo Henrique; SOUSA, Renato Tarciso Barbosa de. O controle de documentos arquivísticos em trâmite: entrada, registro, movimentação e saída. ÁGORA: Arquivologia em debate, v. 27, n. 54, p. 47-81, 2017. . Disponível em: https://engres.org/ra/article/view/616. Acesso: 08 maio 2020.

ARÉVALO JORDAN, V. H. Diccionario de términos archivísticos. Buenos Aires: Ediciones del Sur, 2003. Disponível em: http://www.actiweb.es/itsam/archivo8.pdf. Acesso: 03 mar. 2019.

ARQUIVO NACIONAL. Dicionário brasileiro de terminologia arquivística. Rio de Janeiro: Arquivo Nacional, 2005. Disponível em: http://www.arquivonacional.gov.br/images/pdf/Dicion_Term_Arquiv.pdf. Acesso em: 28 abr. 2020. 
BAPTISTA, J. R. de S. A desconcentração na administração do poder jurídico do Estado do Rio de Janeiro mediante a criação dos núcleos regionais. 2011. Monografia (Especialista em Gestão Pública) - Universidade Candido Mendes, Rio de Janeiro, 2011. Disponível em: http://www.avm.edu.br/docpdf/monografias_publicadas/K218443.pdf. Acesso em: 25 mar. 2019.

BRASIL. Lei no 8.159, de 08 de janeiro de 1991. Dispõe sobre a política nacional de arquivos e provados e dá outras providencias. Diário da República Federativa do Brasil, 1991. Disponível em: http://www.planalto.gov.br/ccivil_03/LEIS/L8159.htm. Acesso em: 24 fev. 2019.

BRASIL. Lei 12.527, de 18 de novembro de 2011. Regula o acesso a informações previsto no inciso XXXIII do art. $5^{\circ}$, no inciso II do $\S 3^{\circ}$ do art. 37 e no $\S 2^{\circ}$ do art. 216 da Constituição Federal; altera a Lei ํㅡ 8.112, de 11 de dezembro de 1990; revoga a Lei no 11.111, de 5 de maio de 2005, e dispositivos da Lei oㅡ 8.159, de 8 de janeiro de 1991; e dá outras providências. Diário da República Federativa do Brasil, 2011. Disponível em: http://www.planalto.gov.br/ccivil_03/_ato2011-2014/2011/lei//12527.htm. Acesso em: 20 mar. 2019.

BRASIL. Portaria Interministerial no 1.677, de 07 de outubro de 2015. Define os procedimentos gerais para o desenvolvimento de atividade de protocolo em âmbito dos órgãos e entidades da Administração Pública Federa. Diário Oficial da União, Brasilia, DF, 07 out 2015. Disponível em: http://www.in.gov.br/materia/-/asset_publisher/Kujrw0TZC2Mb/ content/id/33258545/do1-2015-10-08-portaria-interministerial-n-1-677-de-7-deoutubro-de-2015-33258536. Acesso em: 28 abr. 2020.

CAMARGO, Ana Maria de Almeida. BELLOTTO, Heloísa Liberalli (coord.). Dicionário de terminologia arquivística. São Paulo: Associação dos Arquivistas Brasileiros. Núcleo Regional de São Paulo/Secretaria de Estado da Cultura. Departamento de Museus e Arquivos, 1996.

CHIAVENATO, I. Introdução à teoria geral da administração: uma visão abrangente da moderna administração das organizações: uma visão abrangente da moderna administração das organizações. Rio de Janeiro: Elsevier Brasil, 2003. Disponível em: https://profeltonorris.files.wordpress.com/2014/02/livro-teoria-geral-daadministrac3a7c3a3o.pdf. Acesso em: 28 abr. 2020.

DURANTI, Luciana; PRESTON, Randy. International research on permanent authentic records in electronic systems (InterPARES) 2: Experiential, interactive and dynamic records. Padua, Italy: CLEUP, 2008. Disponível em: http://www.interpares.org/ip2/display_file.cfm?doc=ip2_book_complete.pdf Acesso em: 8 maio 2020. 
FREIXO, A. L. Gestão de arquivos da administração Pública do Estado da Bahia: da prática burocrática ao discurso gerencialista. 2007. Dissertação (Mestrado em Ciência da Informação) - Universidade Federal da Bahia, Salvador, 2007. Disponível em: https://repositorio.ufba.br/ri/bitstream/ri/7906/1/FREIXO\%20A_Gestao\%20de\% 20Arquivos.pdf. Acesso em: 28 abr. 2020

GARCÍA DE BENEDICTIS, A. V. Glosario de terminologia archivística costarricense. Revista del Archivo Nacinal, v. 58, n. 1-12, p. 9-35, 1994. Disponível em: http://www.dgan.go.cr/ran/index.php/RAN/article/view/316. Acesso em: 28 abr. 2020.

INTERNATIONAL COUNCIL ON ARCHIVES. Multilingual archival terminology. Disponível em: http://www.ciscra.org/mat/mat Acesso em: 8 maio 2020

INDOLFO, A. C. Gestão de documentos: uma renovação epistemológica no universo da arquivologia. Arquivística.net, Rio de Janeiro, v. 3, n. 2, jul./dez., 2007. Disponível em: http://www.brapci.inf.br/index.php/article/download/3553. Acesso em: 29 dez. 2018.

JUNQUEIRA, L. A. P. Descentralização e intersetorialidade: a construção de um modelo de gestão municipal. Revista Administração Pública, Rio de Janeiro, v. 32, n. 2, p. 11-22, 1998. Disponível em:

http://bibliotecadigital.fgv.br/ojs/index.php/rap/article/view/7696. Acesso em: 04 jan. 2019

KLERING, L. R.; PORSSE, M. de C. S.; GUADAGNIN, L. A. Novos caminhos da administração Pública Brasileira. Análise, Porto Alegre, v. 21, n. 1, jan./jun., p. 4-17, 2010. Disponível em:

https://www.researchgate.net/publication/277097960_Novos_Caminhos_da_Ad ministracao_Publica_Brasileira. Acesso em: 29 mar. 2019

MACHADO, H. C.; CAMARGO, A. M. de A. Como implantar arquivos públicos municipais. São Paulo: Arquivo do Estado, 1999. (Projeto como fazer: v. 3)

PEARCE-MOSES, Richard. A glossary of archival and records terminology. Chicago, IL: Society of American Archivists, 2005. Disponível em: http://www.chismechick.com/wp-content/uploads/2017/08/SAA-Glossary2005.pdf. Acesso em: 21 mar. 2019.

SCHÄFER, A. C. Quando a tradução (re)conta a História: análise textual e tradução comentada de interrogatórios da "Rosa Branca". 2015. Dissertação (Mestre em Língua e Literatura Alemã) - Universidade de São Paulo, São Paulo. 2015. Disponível em: https://www.teses.usp.br/teses/disponiveis/8/8144/tde-23112015133329/publico/2015_AnnaCarolinaSchafer_VCorr.pdf. Acesso em: 28 abr. 2020. 


\title{
PROTOCOL MANAGEMENT: A THEORETICAL PROPOSAL OF NEW ORGANIZATIONAL MODELS FOR PUBLIC ADMINISTRATION
}

\begin{abstract}
Introduction: In the context of Document Management it is necessary to understand the relevance of the Protocol service and the possibilities to optimize its processes with the adaptation and implementation of organizational models in these services. Objective: Demonstrate new organizational models for carrying out Protocol activities. Using the theoretical debates under the Protocol, centralization, decentralization and deconcentration from the perspective of the Archivology, in order to list the elements that support the importance of the use of the organizational models in the Protocol and to understand how the choice of a model will affect the management program of documents of an organization and list possible obstacles that may occur with the implementation of each model. Methodology: Bibliographic research in printed and electronic documents, with authors of the Archivology and Administration on the subjects Document Management, Protocol and Organizational Models. Results: The research presents advantages and disadvantages of organizational models in a possible application in a Protocol service. Conclusions: Based on the discussions, it was possible to observe the intrinsic relationship of codependency between Document Management and the Protocol service, emphasizing the need for a singular attention to the application of an organizational model that allows to maximize functionality and efficiency in the provision of services.
\end{abstract}

Descriptors: Protocol. Archives. Document management. Organizational Models.

\section{GESTIÓN DE PROTOCOLO: UNA PROPUESTA TEÓRICA DE NUEVOS MODELOS ORGANIZACIONALES PARA LA ADMINISTRACIÓN PÚBLICA}

\section{RESUMEN}

Introducción: En el contexto de la Gestión de Documentos se hace necesario comprender la relevancia del servicio de Protocolo y las posibilidades de optimizar sus procesos con la adaptación e implementación de modelos organizacionales en esos servicios. Objetivo: Demostrar nuevos modelos organizativos para la realización de las actividades de Protocolo. Utilizando los debates teóricos bajo el Protocolo, centralización, descentralización y desconcentración en la perspectiva de la Archivología, a fin de enumerar los elementos que respaldan la importancia de la utilización de los modelos organizativos en el Protocolo y entender cómo la elección de un modelo afectará el programa de gestión de documentos de una organización y establecer posibles trabas que pueden ocurrir con la implementación de cada modelo. Metodología: Investigación Bibliográfica en documentos impresos y electrónicos, con autores de la Archivología y Administración acerca de las temáticas Gestión de documentos, Protocolo y Modelos organizacionales. Resultados: La investigación presenta ventajas y desventajas de los modelos organizacionales en una posible aplicación en un servicio de protocolo. Conclusiones: A partir de las discusiones abordadas fue posible observar la intrínseca relación de codependencia entre la Gestión 
Documental y el servicio de Protocolo, resaltando la necesidad de una atención singular para la aplicación de un modelo organizacional que posibilite maximizar la funcionalidad y la eficacia en la prestación de los servicios.

Descriptores: Protocolo. Gestión de documentos. Modelos organizacionales. Descentralización. Centralización. Desconcentración.

Recebido em: 28.06.2019

Aceito em: 17.08 .2019 